Research letter

\title{
Antimicrobial activity of branched oligo(hexamethyleneguanidine) hydrochloride on oral pathogens
}

\author{
Denis O. Shatalov ${ }^{1}$, Stanislav A. Kedik ${ }^{1}$, Alexey V. Panov ${ }^{1}$, Elena S. Zhavoronok ${ }^{1}$, Anna V. Aydakova ${ }^{1}$, \\ Alena V. Kovalenko ${ }^{1}$, Olga A. Morozova ${ }^{2}$, Irina M. Makeeva ${ }^{2}$, Viktoria A. Dezhurko-Korol ${ }^{2}$ \\ ${ }^{1}$ Moscow Technological University, Moscow, Russia \\ ${ }^{2}$ I.M. Sechenov First Moscow State Medical University, Moscow, Russia
}

Received 15 August 2017, Revised 8 April 2018, Accepted 14 April 2018

(C) 2017, Shatalov D.O., Kedik S.A., Panov A.V., Zhavoronok E.S., Aydakova A.V., Kovalenko A.V., Morozova O.A., Makeeva I.M., Dezhurko-Korol V.A. C 2017, Russian Open Medical Journal

\begin{abstract}
The present work is devoted to study of the antimicrobial activity of a new promising synthetic biocidal compound, branched oligohexamethylene guanidine hydrochloride. The studies were carried out using optional anaerobic bacteria Staphylococcus aureus and Klebsiella pneumoniae, as well as obligate anaerobic bacteria Actinomyces pyogenes, Actinomyces odontolyticus, Peptostreptococcus micros, Finegoldia magna, Veillonella parvula, Prevotella disiens and Fusobacterium nucleatum. It was shown that branched oligohexamethylene guanidine hydrochloride inhibits the growth of these bacteria, and facultative anaerobic bacteria are more sensitive to it. The assumptions about the mechanism of this activity of branched oligohexamethylene guanidine hydrochloride are made. The results of the study show that the substance can be recommended as a broad-spectrum biocide.
\end{abstract}

Keywords: branched oligo(hexamethyleneguanidine) hydrochloride, antimicrobial activity, oral pathogens.

Cite as Shatalov DO, Kedik SA, Panov AV, Zhavoronok ES, Aydakova AV, Kovalenko AV, Morozova OA, Makeeva IM, Dezhurko-Korol VA. Antimicrobial activity of branched oligo(hexamethyleneguanidine) hydrochloride on oral pathogens. Russian Open Medical Journal $2018 ; 7$ : e0309.

Correspondence to Denis O. Shatalov. E-mail: shat-05@mail.ru.

\section{Introduction}

Dental diseases are among the most prevalent and costly diseases affecting industrialized societies, and yet are highly preventable. For example, in the UK, the National Health Service spends over $£ 1,6$ billion per annum on dental treatment, and this figure increases to $£ 2,6$ billion if the burgeoning private sector costs are included [1, 2].

Oral pathogens are microorganisms on the oral surface that play an important part in the development of caries and periodontal diseases $[3,4]$. It is now clear that microorganisms play an essential role in the pathogenesis of dental caries and consequently provides a prime target for the prevention of this disease by antibiotics and vaccine $[5,6]$.

Most active pharmaceutical ingredients (API) have highly targeted specific mechanisms of action and interfere with one particular cellular function such as cell wall synthesis, protein or RNA synthesis, DNA replication or energy metabolism [7-10]. Drugs are widely used in humans and animals, resulting in the increasing emergence of resistant bacterial strains. Bacteria can be intrinsically resistant to certain substances or can overcome susceptibility by genetic adaptation. Hence the development of new generation antibiotics is a high unmet medical need [7], especially in dental care.

Modern antiseptics containing chlorhexidine that are commonly used in dentistry are known to stain teeth, composite restorations and dorsum of the tongue. They often cause taste sensitivity distortion. If used longer than 14 days, they might lead to disbiotic changes. Hence new active materials are needed.

New promising candidates under development as alternatives for existing API are the synthetic guanidine-based polymers, with a new physicochemical mechanism of action and favorable toxicological properties.

One of the emerging classes of guanidine-based polymers belongs to the branched oligomers of hexamethylenediamine and guanidine which have been in use mainly as antiseptics, surface disinfectants and topical antimicrobials for over 80 years within clinical, industrial and domestic hygiene delivery [11].

Branched oligo(hexamethyleneguanidine) (OHMG) hydrochloride (Figure 1) can be used in medical practice for treating viral and infectious dental diseases because of their highly effective action and low toxicity [11-13].

The aims of the present investigation were to assess the antimicrobial activities of the branched OHMG hydrochloride on main oral pathogens.

\section{Material and Methods \\ Microorganisms}

Bacterial reference strains used in this research are Staphylococcus aureus ATCC 29213, Klebsiella pneumoniae ATCC 13883, Actinomyces pyogenes ATCC 49698, Actinomyces odontolyticus ATCC 17929, Actinomyces israellii ATCC 12102, Peptostreptococcus micros ATCC 33270, Veillonella parvula ATCC 
10790, Fusobacterium nucleatum ATCC 25586; and strains of microorganisms isolated from clinical specimens: Finegoldia magna №1109, Peptostreptococcus anaerobius №1116/2 and Prevotella disiens №1116/3. The source of the strains is the interclinical bacteriological laboratory of I.M. Sechenov First Moscow State Medical University (Moscow, Russia).

This choice of microorganisms is due to the published data [14, 15] and the results of research in our laboratory. The organisms selected for the study are frequent causative agents of infectiousinflammatory processes in patients with various purulentinflammatory diseases of maxillofacial area.

\section{Branched OHMG hydrochloride}

Sample of branched OHMG hydrochloride ("DEZAPOL") was obtained from Institute of Pharmaceutical Technologies (Moscow, Russia), number-average OHMG molecular weight is $750 \mathrm{Da}$, average number of branchings is 0.25 to per molecule [12].

We have prepared several solutions from OHMG hydrochloride for evaluation of antimicrobial activity.

\section{Antimicrobial activity assay}

Examination of the bactericidal activity of the $0.1 \%, 0.2 \%$ and $0.5 \%$ water solution of the OHMG hydrochloride $[2,4,7]$

For the cultivation of the $S$. aureus, K. pneumoniae there was used Brain Heart Infusion agar (Conda, Spain) with 5\% blood, obligate anaerobes - Brucella agar (Becton, Dickinson and Company, USA) supplemented with vitamin $\mathrm{K}$, hemin and $5 \%$ lysed horse blood and incubated at $37^{\circ} \mathrm{C}$ for $24-48 \mathrm{~h}$.

For the preparation of the bacterial suspensions net daily culture of microorganisms diluted in sterile $0.9 \%$ chloride solution sodium until a turbidity equivalent to a 0.5 standard the McFarland (approximately $1.5 \times 10^{8} \mathrm{CFU} / \mathrm{ml}$ ).

Then there were prepared tenfold broth solutions with the final concentration of approximately $1,0 \times 106 \mathrm{CFU} / \mathrm{ml}$, - in the Miller-Hinton broth for facultative anaerobes and enriched thioglycollate medium (BD, USA) - for obligate anaerobes from our solutions mentioned above.

The prepared broth cultures of each test-microorganism were poured in 4 test tubes of $1 \mathrm{ml}$ each. In the test tubes No. 1, 2, 3 there were poured $1 \mathrm{ml} 0.1 \%, 0.2 \%$ and $0.5 \%$ of water solutions of the OHMG hydrochloride. The final concentration of the OHMG in the test tubes No. 1, 2, 3 was respectively $0.05 \%, 0.10 \%$ and $0.25 \%$.

For the control there was used the test tube No. 4 with the culture where to instead of the OHMG solution there was added 1 $\mathrm{ml}$ of the relevant broth. All the samples were incubated in a thermostat at $36^{\circ} \mathrm{C}$, the incubation of the obligate anaerobic bacteria was done in a jar with the use of the GasPak System (BD, USA), after 24-72 hours they were plated in the dense nutrient medium for detection of the bacterial concentration. After 24-72 hours of incubation of plates with inoculations and depending on the type of microorganisms there was calculated a number of appeared colonies and the bacterial concentration was detected.

Determination of minimal inhibitory concentration (MIC) of branched OHMG hydrochloride

The sensitivity of $S$. aureus, K. pneumoniae was determined by the standard broth macrodilution method. Strains were tested in the cationon-balanced Mueller-Hinton broth (BD, USA) [16, 17].

During the examination of the MIC there was used the $0.5 \%$ $(5000 \mu \mathrm{g} / \mathrm{ml})$ solution of the OHMG as a basic solution out of which there was prepared a working solution $-500 \mu \mathrm{g} / \mathrm{ml}$, with the following twofold dilutions in the Muller-Hinton broth.

The inoculum of test strains is prepared similarly to the preceding examination in the concentration of $1.0 \times 10^{6} \mathrm{CFU} / \mathrm{ml}$.

In the test tubes with prepared dilutions of the OHMG $(1 \mathrm{ml})$, there is added the suspension of the agar culture of the examined bacteria in the Muller-Hinton broth in the volume of $1 \mathrm{ml}$. After addition of the bacteria culture, the test tubes are incubated at the temperature $36^{\circ} \mathrm{C}$ for $24-48$ hours.

The detection of the MIC was estimated on the absence of growth in the medium containing the least concentration of the branched OHMG hydrochloride.

The detection of the MIC of the obligate anaerobic bacteria was determined by the agar dilution method $[18,19]$.

During the examination of the MIC of the obligate aerobes, there was also used the branched OHMG hydrochloride 0.5\% $(5000 \mu \mathrm{g} / \mathrm{ml})$ solution in the capacity of the basic solution out of which the series of twofold diminishing concentrations are prepared. In the liquefied Brucella agar $(17 \mathrm{ml})$ there is sequentially added $2 \mathrm{ml}$ of each the branched OHMG hydrochloride dilution and $1 \mathrm{ml}$ of laced blood.

The microbe's suspension containing about $1-2 \times 10^{8} \mathrm{CFU} / \mathrm{ml}$ of examined microorganisms is prepared similar to the preceding examination and in the volume of $0.5 \mu \mathrm{l}$ is placed on the surface of the agar with various concentrations of the branched OHMG hydrochloride. After the placing of the germ culture, the plates are incubated at the temperature of $36^{\circ} \mathrm{C}$ for 72 to 108 hours in anaerobic conditions.

The detection of the MIC is estimated according to the absence of the growth on the plate with the medium containing the least concentration of the branched OHMG hydrochloride.

The experiment was performed three times for each concentration of the branched OHMG hydrochloride in each type of microorganisms.

Determination of the influence of branched OHMG hydrochloride on bacterial membranes

To determine the effect of the OHMG on the permeability of bacterial membranes for external substances, the bacteria were cultured for 24 hours in culture medium CASO agar (Sigma-Aldrich, Germany) at $+36^{\circ} \mathrm{C}$ for $20-24$ hours (S. aureus and K. pneumoniae) or in CASO agar supplemented with $0.1 \%$ cysteine in anaerobic conditions at $+36^{\circ} \mathrm{C}$ for 3 days (A. odontolyticus and F. nucleatum). Bacteria were washed twice by precipitation by centrifugation $(4000 \mathrm{~g}$, $3 \mathrm{~min}$ ) and resuspension in saline, and then resuspended in saline until the final density of the suspension was about $109 \mathrm{CFU} / \mathrm{ml}$. The bacterial suspension was mixed with an equal volume of water containing fluorescent dyes LIVE/DEAD (10 $\mu \mathrm{M}$ SYTO 9 Green Fluorescent Nucleic Acid Stain (Invitrogen, ThermoFischer Scientific, USA) and $60 \mu \mathrm{M}$ propidium iodide (Invitrogen, ThermoFischer Scientific, USA) and OHMG (control without OHMG), incubated for 15 min at room temperature, and then $3 \mu$ of the suspension was applied to the slide, covered with a coverslip and visualized using an EVOS fluorescence microscope FLoid cell imaging station (ThermoFischer Scientific, USA). The resulting images were processed using the Fiji program as follows. To obtain representative images, the brightness 
and contrast of the green and red channels were adjusted in such a way that when the channels were down, the intensity of the green and red color was comparable. For the quantitative processing of images, the brightness and contrast of the green and red channels were adjusted in such a way as to isolate the bacteria and their aggregates and to remove the background. After that, the images were binarized, the bacteria and their aggregates were detected using the analyze particles function, counting the number of bacteria and aggregates and their total area.

\section{Results}

Examination of the bactericidal activity of the $0.1 \%, 0.2 \%$ and $0.5 \%$ water solution of the OHMG hydrochloride

Table 1 presents the data on the bactericidal effects of a water solution of the branched OHMG hydrochloride on the tested microorganisms in three concentrations. As seen from Table 1, aqueous solutions of $0.05 \%-0.25 \%$ possess bactericidal activity against all the studied microorganisms. The investigated solutions caused $100 \%$ death of ten of the eleven species. In the study, K. pneumoniae - water solution of the OHMG hydrochloride $0.05 \%$ and $0.1 \%$, causing the death of $99.90 \%$ and $99.96 \%$ of bacterial cells $K$. pneumoniae, during the second study found no growth increase in this type of microorganisms.

\section{Determination of MIC of branched OHMG hydrochloride}

The values of the MIC of branched OHMG hydrochloride shown in Table 2.

The results present in Table 2 indicate, that MIC of branched OHMG hydrochloride has a range $0.5-250.0 \mu \mathrm{g} / \mathrm{ml}$. MIC-values of sample of facultative anaerobic microflora (S. aureus ATCC 29213, K. pneumoniae ATCC 13883) was the lowest concentration which we have. Fusobacterium nucleatum ATCC 25586 and Prevotella disiens №1116/3 were most susceptible to branched OHMG hydrochloride, from obligate anaerobes.

Determination of the influence of branched OHMG-HC on bacterial membranes

To determine the effect of the OHMG on the permeability of bacterial membranes to external substances, the bacterial suspension was incubated for 15 minutes in the presence of $20 \mu \mathrm{g} / \mathrm{ml}$ of the OHMG and fluorescent dyes LIVE/DEAD. The mixture of LIVE/DEAD dyes consists of two components: the green fluorescent dye SYTO 9 and the red fluorescent dye propidium iodide (PI). Both dyes fluoresce only after binding to DNA, while SYTO 9 has the ability to penetrate into cells, while PI is unable to pass through intact cell membranes and only penetrates into cells whose membranes are damaged. Thus, living cells with intact membranes are colored green, while cells in which the integrity of the membranes are broken are colored at once green and red, or only red due to excess of PI.

The figures show data for some selected crops. Both facultatively aerobic strains demonstrate an increase in membrane permeability for PI with simultaneous incubation with $20 \mu \mathrm{g} / \mathrm{ml}$ of OHMG and LIVE/DEAD dyes compared to incubation without OHMG (Figure 1).

To quantify this effect, the number of cells and aggregates stained with SYTO 9 (green) or PI (red), as well as their total area, and the ratio of these values for each image obtained, were counted. The data are given in Table 3.
Table 1. Bactericidal activity of water solution of the OHMG hydrochloride

\begin{tabular}{lccc}
\hline \multirow{2}{*}{ Bacterium } & \multicolumn{3}{c}{ Viable count, CFU/ml } \\
\cline { 2 - 4 } & \multicolumn{3}{c}{ Final concentration of w.s. of } \\
& \multicolumn{2}{c}{ OHMG hydrochloride: } \\
& $0.05 \%$ & $0.10 \%$ & $0.25 \%$ \\
\hline Actinomyces pyogenes ATCC 49698 & n.g. & n.g. & n.g. \\
Actinomyces odontolyticus ATCC 17929 & n.g. & n.g. & n.g. \\
Actinomyces israellii ATCC 2102 & n.g. & n.g. & n.g. \\
Peptostreptococcus micros ATCC 33270, & n.g. & n.g. & n.g. \\
Finegoldia magna №1109 & n.g. & n.g. & n.g. \\
Peptostreptococcus anaerobius №1116/2 & n.g. & n.g. & n.g. \\
Veillonella parvula ATCC 10790 & n.g. & n.g. & n.g. \\
Fusobacterium nucleatum ATCC 25586 & n.g. & n.g. & n.g. \\
Prevotella disiens №1116/3 & n.g. & n.g. & n.g. \\
S. aureus ATCC 29213 & n.g. & n.g. & n.g. \\
K. pneumoniae ATCC 13883 & 5.0x10 & $2.0 \times 10^{2}$ & n.g. \\
\hline
\end{tabular}

w.s., water solution; n.g., no growth.

Table 2. Determination of MIC of branched OHMG hydrochloride

\begin{tabular}{lc}
\hline \multicolumn{1}{c}{ Bacterium } & MIC OHMG $\mu \mathrm{g} / \mathrm{ml}$ \\
\hline Actinomyces pyogenes ATCC 49698 & 250.0 \\
Actinomyces odontolyticus ATCC 17929 & 125.0 \\
Actinomyces israellii ATCC 12102 & 250.0 \\
Peptostreptococcus micros ATCC 33270 & 250.0 \\
Finegoldia magna №1109 & 250.0 \\
Peptostreptococcus anaerobius №1116/2 & 125.0 \\
Veillonella parvula ATCC 10790, & 125.0 \\
Fusobacterium nucleatum ATCC 25586 & 31.3 \\
Prevotella disiens №1116/3 & 62.5 \\
S.aureus ATCC 29213 & $0.5-1.0$ \\
K.pneumoniae ATCC 13883 & 4.0 \\
\hline
\end{tabular}

Table 3. The influence of $20 \mu \mathrm{g} / \mathrm{ml}$ of OHMG on the permeability of bacterial membranes for $P I$

\begin{tabular}{lcc:cc}
\hline Bacterium & \multicolumn{2}{c}{ G/R ratio (number) } & $G / R$ ratio (area), control \\
& control & $\begin{array}{c}20 \mu \mathrm{g} / \mathrm{ml} \\
\mathrm{OHMG}\end{array}$ & control & $\begin{array}{c}20 \mu \mathrm{g} / \mathrm{ml} \\
\text { OHMG }\end{array}$ \\
\hline S. aureus & $11.8 \pm 10.3$ & $1.0 \pm 0.0$ & $15.4 \pm 17.7$ & $1.4 \pm 0.2$ \\
K. pneumoniae & $31.4 \pm 16.4$ & $1.8 \pm 0.3$ & $118.8 \pm 86.6$ & $2.4 \pm 0.6$ \\
A. odontolyticus & $3.4 \pm 1.9$ & $0.8 \pm 0.1$ & $7.7 \pm 5.1$ & $0.9 \pm 0.1$ \\
F. nucleatum & $12.7 \pm 9.4$ & $18.6 \pm 12.1$ & $18.3 \pm 12.8$ & $19.5 \pm 8.7$ \\
\hline
\end{tabular}

$\mathrm{G} / \mathrm{R}$ ratio (number), the ratio of the number of green cells/aggregates to red (ratio value is presented with standard deviation); G/R ratio (area), the ratio of the area of green cells/aggregates to red (ratio value is presented with standard deviation).

\section{Discussion}

At present, a large number of synthetic biocidal compounds are known to fight the pathogenic microflora. These include antibiotics [20], quaternary ammonium bases [21-24], compounds of phenolic series [25-27] and some others. However, in modern works $[8,28-34]$ it is shown that in different microorganisms, with respect to these substances, resistance is developed sooner or later. This prevents good treatment. A new type of synthetic biocides to which resistance is not developed in microorganisms are guanidine compounds such as chlorhexidine salts [35-37], alexidine [38, 39] and polyguanidines [40]. 

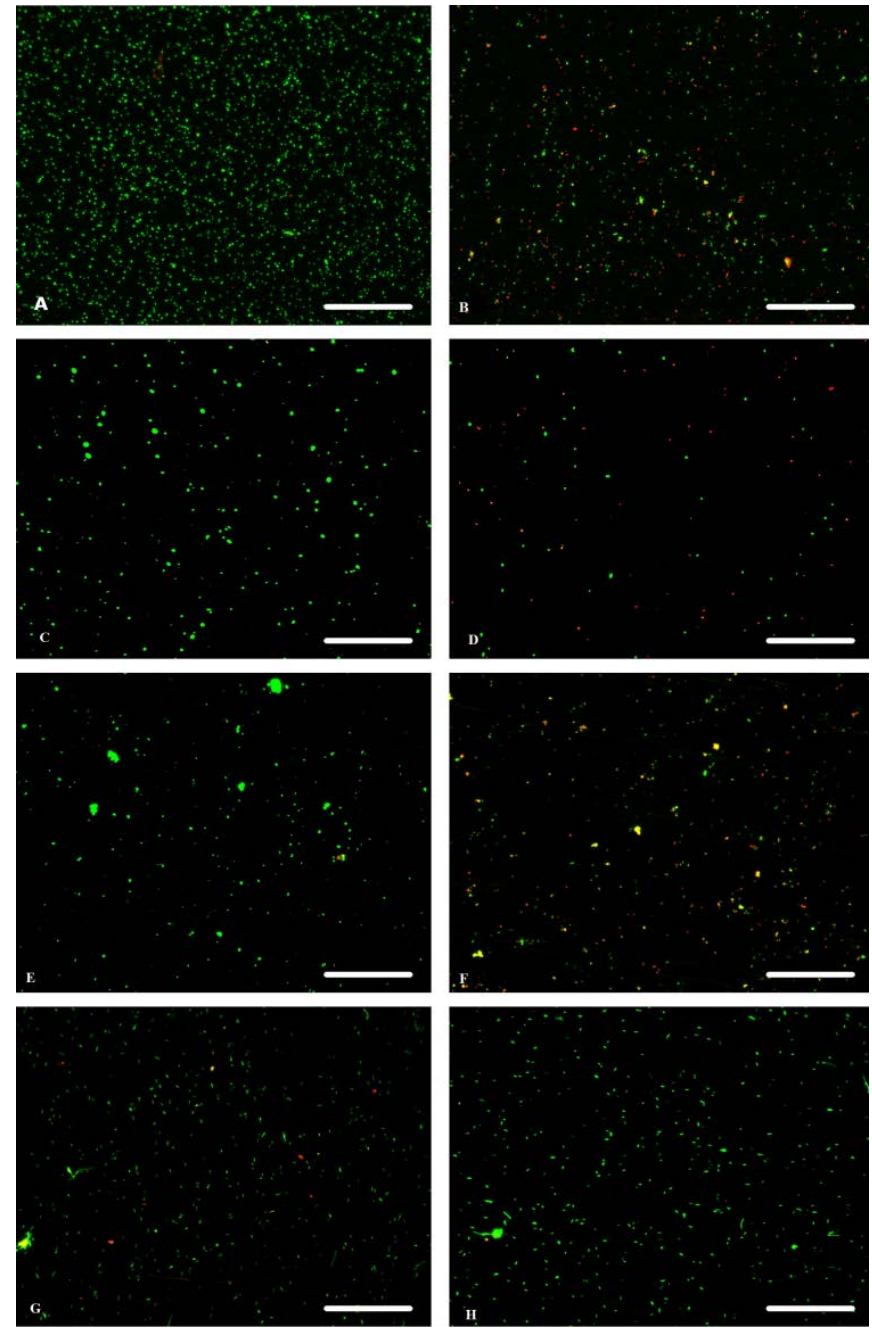

Figure 1. Microphotographs of bacteria after simultaneous treatment with LIVE/DEAD dyes and $20 \mu \mathrm{g} / \mathrm{ml}$ OHMG. On the left are photographs with dying, on the right trearment with the OHMG hydrochloride solution: A, B - S. aureus; C, D - K. pneumoniae; E, F-A. odontolyticus; G, $\mathrm{H}-\boldsymbol{F}$. nucleatum. The size of the ruler is $100 \mu \mathrm{m}$.

Preliminary studies [41] show that one of the promising compounds exhibiting biocidal activity against aerobic and anaerobic microflora can be partially branched oligohexamethyleneguanidine hydrochloride. It is believed that the partially branched OHMG hydrochloride has a lower toxicity and corrosive activity than its linear counterparts [40]. At the heart of its action, apparently, is the interaction of positively charged guanidine fragments with negatively charged sites of the peptidoglycan layer of the bacterial cell [42]. As a result of this interaction, the integrity of the outer membrane of the cell is broken, and it collapses. Our studies (Figure 1) confirm this assumption, indicating the destruction of cell membranes under the action of the branched OHMG hydrochloride.

This study shows that branched OHMG hydrochloride has a pronounced antimicrobial effect against various bacterial strains. Aqueous solutions of branched OHMG hydrochloride $0.05-0.25 \%$ have bactericidal activity against all tested species of microorganisms (Table 1), which are the main types of pathogenic microflora in the oral cavity. Taking into account the low toxicity of branched OHMG hydrochloride, its aqueous solutions can be recommended as an active component of ready-made dosage forms for the treatment and prevention of inflammatory diseases of the oral cavity.

However, the effect of the branched OHMG hydrochloride on different types of microorganisms investigated is not the same. Based on the analysis of individual values of MIC (Table 2), it can be concluded that the antiseptic in question is different in relation to different types of microorganisms. Individual MIC values vary widely (from $0.5 \mu \mathrm{g}$ to $250.0 \mu \mathrm{g} / \mathrm{ml}$ of antiseptic), with facultative anaerobic bacteria (Staphylococcus aureus and Klebsiella pneumoniae) more sensitive to the action of branched OHMG hydrochloride, compared to obligate anaerobic (Actinomyces pyogenes, Actinomyces odontolyticus, Actinomyces israellii, Peptostreptococcus anaerobius, Peptostreptococcus micros, Finegoldia magna, Veillonella parvula, Prevotella disiens and Fusobacterium nucleatum). The results of the experiment indicate that branched OHMG hydrochloride is more active against gramnegative bacilli among the mandatory anaerobes (Prevotella disiens and Fusobacterium nucleatum).

\section{Conclusion}

Data of the present study indicate that branched OHMG hydrochloride has potential as new candidate which can be used in medical practice for treating viral and infectious dental diseases because it has possessed a wide antimicrobial spectrum.

Acknowledgments

Many thanks to the Institute of Pharmaceutical Technologies (Moscow, Russia) for their support.

\section{Conflict of interest}

The authors declare that they have no conflict of interest.

\section{Ethical approval}

For this type of study formal consent is not required. This article does not contain any studies with human participants or animals performed by any of the authors.

\section{References}

1. Marsh PD. Are dental diseases examples of ecological catastrophes? Microbiology 2003; $279-294$. http://dx.doi.org/10.1099/mic.0.26082-0.

2. Asikainen $\mathrm{S}$, Chen $\mathrm{C}$. Oral ecology and person-to-person transmission of Actinobacillus actinomycetemcomitans and Porphyromonas gingivalis. Periodontol 1999; 20; 65-81. http://dx.doi.org/10.1111/j.1600-0757.1999.tb00158.x.

3. Meyer DH, Fives-Taylor PM. Oral pathogens: from dental plaque to cardiac disease. Curr Opin Microbiol 1998; 1; 88-95. http://dx.doi.org/10.1016/S1369-5274(98)80147-1.

4. Veloo ACM, Seme K, Raangs E, Rurenga $P$, Singadji Z, Wekema-Mulder $G$, van Winkelhoff AJ. Antibiotic susceptibility profiles of oral pathogens. Int J Antimicrob Agents 2012; 40; 450-454. http://dx.doi.org/10.1016/j.ijantimicag.2012.07.004.

5. Park YK, Koo MH, Abreu JA, Ikegaki M, Cury JA, Rosalen PL. Antimicrobial activity of propolis on oral microorganisms. Curr Microbiol 1998; 36; 24-28. http://dx.doi.org/10.1007/s002849900274.

6. Bowen WH. Dental caries in monkeys. Adv Oral Biol 1968; 3; 185-216. http://dx.doi.org/10.1016/B978-1-4832-3119-8.50013-5. 
7. Pasberg-Gauhl C. A need for new generation antibiotics against MRSA resistant bacteria. Drug Discov Today Technol 2014; 11; 109-116. http://dx.doi.org/10.1016/i.ddtec.2014.04.001.

8. Walsh CT. Molecular mechanisms that confer antimicrobial drug resistance. Nature 2000; 406; 775-781. http://dx.doi.org/10.1038/35021219.

9. Walsh C. Antibiotics: actions, origins, resistance. American Society for Microbiology (ASM), 2003. http://dx.doi.org/10.1128/9781555817886.

10. Skold O. Antibiotics and antibiotic resistance. John Wiley and Sons Inc, 2011. http://dx.doi.org/10.1002/9781118075609.

11. Kedik SA, Sedishev IP, Panov AV. Branched oligomers on the basis of a guanidine derivative and disinfecting agent containing said oligomers (alternatives), WO/2012/082009 PCT/RU2011/000536, 21.06.2012. https://patentscope.wipo.int/search/ru/detail.jsf?docld=WO20120820 $\underline{09}$.

12. Kedik SA, Bocharova OA, An HK, Panov AV, Sedishev IP, Zhavoronok ES, et al. Structure and molecular-weight characteristics of oligo(hexamethyleneguanidine) hydrochlorides. Pharmaceutical Chemistry Journal 2011; 44(10); 568-573. https://doi.org/10.1007/s11094-011-0519-9.

13. Kedik SA, Shatalov DO, Panov AV. Development and validation of the method to control guanidine hydrochloride monomer impurities in pharmaceutical substance "branched oligohexamethyleneguanidine hydrochloride". Vestnik MITHT (Fine Chem Tech) 2014; 9(2); 32-36. Russian. https://elibrary.ru/item.asp?id=21495106.

14. Kovaleva NS, Zabelin AS, Zuzova AP. Pharmacoepidemiologic, clinical and microbiological study on antimicrobial therapy of inflammatory diseases of maxillofacial area. Clinical Microbiology and Antimicrobial Chemotherapy 2011; 13(4); 360-367. Russian. https://elibrary.ru/item.asp?id=17098553.

15. Shipskii AV, Afanasiev VV, Polikarpov NA, Efimov KM, Dmitruk IB. Comparative analysis of antimicrobial action of polyhexamethylene guanidine hydrochloride (Biopag) and chlorhexidine bigluconate on potential pathogens of inflammatory diseases of maxillofacial area and neck. Stomatologiia (Mosk) 2007; 86(3): 46-50. https://www.ncbi.nlm.nih.gov/pubmed/17690643.

16. Guidelines for susceptibility testing of microorganisms to antibacterial agents. MUK 4.2.1890-04, MH RF, 2004: 7-18.

17. GOST R ISO 20776-1-2010. Clinical laboratory testing and in vitro diagnostic test systems. Susceptibility testing of infectious agents and evaluation of performance of antimicrobial susceptibility test devices. Part 1. Reference method for testing the in vitro activity of antimicrobial agents against rapidly growing aerobic bacteria involved in infectious diseases. Standartinform, 2011: 1-17. https://www.iso.org/standard/41630.html.

18. Polyak MS. Laboratory support of antibiotic therapy. St. Petersburg, Russia: Analytics, 2012: 23-48, 135-164. Russian.

19. Isenberg HD. Clinical microbiology procedures handbook. American Society for Microbiology (ASM), 2007; 1, Section 5: 5.9, 5.16. http://dx.doi.org/10.1128/9781555817435.

20. Leekha S, Terrell CL, Edson RS. General principles of antimicrobial therapy. Mayo Clin Proc 2011; 86(2): 156-167. http://dx.doi.org/10.4065/mcp.2010.0639.

21. Akimitsu $N$, Hamamoto $H$, Inoue $R$, Shoji $M$, Akamine A, Takemori K, et al. Increase in resistance of methicillin-resistant Staphylococcus aureus to beta-lactams caused by mutations conferring resistance to benzalkonium chloride, a disinfectant widely used in hospitals. Antimicrob Agents Chemother 1999; 43(12): 3042-3043. https://www.ncbi.nlm.nih.gov/pubmed/10651623.

22. Dixon RE, Kaslow RA, Mackel DC, Fulkerson CC, Mallison GF. Aqueous quaternary ammonium antiseptics and disinfectants. Use and misuse. JAMA 1976; 236(21): 2415-2417. http://dx.doi.org/10.1001/jama.1976.03270220035031.

23. Hoffman HP, Geftic SG, Gelzer J, Herman H, Adair FW. Ultrastructural alterations in the growth of resistant Pseudomonas aeruginosa in the presence of benzalkonium chloride. J Bacteriol 1973; 113: 409-416. https://www.ncbi.nlm.nih.gov/pubmed/4120070.

24. Russell $A D$. Introduction of biocides into clinical practice and the impact on antibiotic resistance. J App/ Microbiol 2002; 92, Suppl: 121S35S. http://dx.doi.org/10.1046/j.1365-2672.92.5s1.14.x.

25. Davies A, Field BS. Action of biguanides, phenol and detergents on Escherichia coli and its spheroplasts. J Appl Microbiol 1969; 32: 233 243. http://dx.doi.org/10.1111/j.1365-2672.1969.tb00970.x.

26. Denyer SP, Hugo WB, Witham RF. The antibacterial action of a series of 4-n-alkylphenols. Journal of Pharmacy and Pharmacology 1980; 32: 27. http://dx.doi.org/10.1111/j.2042-7158.1980.tb10830.x.

27. Denyer SP, Hugo WB, Harding VD. The biochemical basis of synergy between the antibacterial agents chlorocresol and 2-phenylethanol, International Journal of Pharmaceutics 1986; 29: 29-36. http://dx.doi.org/10.1016/0378-5173(86)90196-1.

28. Chaplin CE. Bacterial resistance to quaternary ammonium disinfectants. J Bacteriol 1952; 63; 453-458. https://www.ncbi.nlm.nih.gov/pubmed/14938318.

29. Chaplin CE. Observations on quaternary ammonium disinfectants. Canadian Journal of Botany 1951; 29; 372-382. http://dx.doi.org/10.1139/b51-036.

30. Davies DS, Hinshelwood CN. The adaptation of Bact. lactis aerogenes to growth in the presence of sulphonamides. Transactions of the Faraday Society 1943; 39: 431-444. http://dx.doi.org/10.1039/tf9433900431.

31. Dubos RJ. Antimicrobial agents of biological origin. JAMA 1944; 124: 633-636. http://dx.doi.org/10.1001/iama.1944.02850100023004.

32. McCulloch EC. False disinfection velocity curves produced by quaternary ammonium compounds. Science 1947; 105: 480-481. http://dx.doi.org/10.1126/science.105.2731.480.

33. McDonnell G, Russell AD. Antiseptics and disinfectants: activity, action, and resistance. Clin Microbiol Rev 1999; 12(1); 147-179. https://www.ncbi.nlm.nih.gov/pubmed/9880479.

34. Weber GR, Black LA. Laboratory procedure for evaluating practical performance of quaternary ammonium and other germicides proposed for sanitizing food utensils. Am J Public Health Nations Health 1948; 38: 1405 1417. http://dx.doi.org/10.2105/AJPH.38.10.1405.

35. Fitzgerald KA, Davies A, Russell AD. Uptake of 14C-chlorhexidine diacetate to Escherichia coli and Pseudomonas aeruginosa and its release by azolectin. FEMS Microbiol Lett 1989; 60: 327-332. https://doi.org/10.1111/j.1574-6968.1989.tb03495.x.

36. Harold FM, Baarda JR, Baron C, Abrams A. Dio 9 and chlorhexidine: inhibition of membrane bound ATPase and of cation transport in Streptococcus faecalis. Biochim Biophys Acta 1969; 183; 129-136. http://dx.doi.org/10.1016/0005-2736(69)90136-9.

37. Hiom SJ, Furr JR, Russell AD, Dickinson JR. Effects of chlorhexidine diacetate on Candida albicans, C. glabrata and Saccharomyces cerevisiae. J Appl Microbiol 1992; 72: 335-340. http://dx.doi.org/10.1111/j.1365-2672.1992.tb01844.x.

38. Chawner JA, Gilbert P. Interaction of the bisbiguanides chlorhexidine and alexidine with phospholipid vesicles: evidence for separate modes of action. J Appl Microbiol 1989; 66: 253-258. http://dx.doi.org/10.1111/i.1365-2672.1989.tb02476.x.

39. Chawner JA, Gilbert P. A comparative study of the bactericidal and growth inhibitory activities of the bisbiguanides alexidine and chlorhexidine. J Appl Microbiol 1989; 66: 243-252. http://dx.doi.org/10.1111/i.1365-2672.1989.tb02475.x.

40. Kedik SA, Sedishev IP, Panov AV, Zhavoronok ES, An HK. Guanidine derivative based branched oligimers and disinfectant containing said oligomers. Patent, RU2443684C1, 2012. https://patentscope.wipo.int/search/ru/detail.jsf?docld=RU75812836.

41. Vointseva II, Gembitsky PA. Polyguanidines - disinfectants and polyfunctional additives. LKM-press, 2009; 304 p. Russian. https://elibrary.ru/item.asp?id=19612469. 
42. Brocato RL, Hammerbeck CD, Bell TM, Wells JB, Queen LA, Hooper JW. A lethal disease model for hantavirus pulmonary syndrome in immunosuppressed syrian hamsters infected with Sin Nombre virus. J Virol 2014; 88(2): 811-819. http://dx.doi.org/10.1128/JVI.02906-13.

\section{Authors:}

Denis O. Shatalov - PhD, Assistant Professor, Department of Biotechnology and Industrial Pharmacy, Institute of Fine Chemical Technology, Moscow Technological University, Moscow, Russia. http://orcid.org/0000-00034510-1721.

Stanislav A. Kedik - DSc, Head of Department of Biotechnology and Industrial Pharmacy, Institute of Fine Chemical Technology, Moscow Technological University, Moscow, Russia. http://orcid.org/0000-00032610-8493.

Alexey V. Panov - PhD, Assistant Professor, Department of Biotechnology and Industrial Pharmacy, Institute of Fine Chemical Technology, Moscow Technological University, Moscow, Russia. http://orcid.org/0000-00021603-143X

Elena S. Zhavoronok - PhD, Assistant Professor, Department of Biotechnology and Industrial Pharmacy, Moscow Technological University, Moscow, Russia. http://orcid.org/0000-0002-7235-3361.

Anna V. Aydakova - MS Student, Institute of Fine Chemical Technology, Moscow Technological University, Moscow, Russia. http://orcid.org/00000002-2560-5028.

Alena V. Kovalenko - MS Student, Institute of Fine Chemical Technology, Moscow Technological University, Moscow, Russia. http://orcid.org/00000001-7642-9055

Olga A. Morozova - PhD, Head of the Inter-Clinical Bacteriological Laboratory, I.M. Sechenov First Moscow State Medical University, Moscow, Russia. http://orcid.org/0000-0002-2498-5292.

Irina M. Makeeva - DSc, Professor, Head of the Department of Therapeutic Stomatology, I.M. Sechenov First Moscow State Medical University, Moscow, Russia. http://orcid.org/0000-0002-7878-0452.

Viktoria A. Dezhurko-Korol - PhD Student, Department of Therapeutic Stomatology, I.M. Sechenov First Moscow State Medical University, Moscow, Russia. http://orcid.org/0000-0002-8587-7965. 